\title{
LANDSLIDE VICTORY FOR COMPUTERS
}

\author{
A. Tridgell \\ Macgregor, Australia \\ Canberra, 14 July 1995
}

A computer team scored a landslide win over their human opponents in the annual Carbon vs Silicon chess tournament at the Australian National University (ANU) in Canberra today. With a final score-line of 19.5 to 5.5 it is an ominous sign of the progress of technology into traditionally human pursuits.

A clear trend has also emerged that reflects the rapid improvements both in hardware and software over the three years that the tournament has been held. In its first year in 1993 the human team scored a sound victory, gaining 14 games to the computers 11 . Last year saw a very close competition with the computers' edging to victory by 1 point in the last game. This year's result showed the computers moving further ahead.

The tournament pits 5 of the top human players in Australia against a mixed bag of 5 chess programs for a prize of AS $\$ 2,000$, winner takes all. This year's human team included an impressive array of talent. The current Australian open chess champion Dinh Doc Trong fared best, scoring wins in 3 of his 5 matches. Other human players included international master Guy West, FIDE master Tim Reilly, South Australian junior champion Neil Steffensen, ANU's star player Roger Farrell, and the ACT's junior champion Rory O'Brian. The computer team, sponsored by Acer, consisted of 4 Pentium-75 PCs and one Pentium-90. This is a considerable advance over the 486-33 PCs used by the majority of programs last year and no doubt contributed to the obvious improvement in play. The chess programs included the current world computerchess champion, FRITZ3, along with CHESS GENIUS 3, MCHESS PRO, HIARCS and the only home-grown contender, DESPERADO. The best performance was produced by CHESS GENIUS 3, with a perfect 5 out of 5 .

During discussions after the tournament over free drinks graciously provided by the winning team, it was widely thought that attitude and playing style of the human players may have had a large influence on the games. The methodical play of Dinh Doc Trong was more effective against the computers than Guy West's attacking style. The impressive play by DESPERADO (written by David Blackman in his spare time over the last six years) has encouraged the organisers to aim for more locally written programs in next year's event. If the current trend continues, however, it may be difficult to find human players willing to risk their pride in such a one-sided contest.

\section{THE 1995 NOVAG AWARD}

The Board of ICCA

In the past, the ICCA has awarded a prize to the author(s) for the publication, which in the opinion of the judges, makes the biggest contribution to computer chess.

For the first six years this award was known as the MEPHISTO AWARD in recognition of the German chesscomputer manufacturer, who generously provided the prizes. As announced in Vol. 18, No. 2, this annual prize could be continued by generosity of the Hong Kong chess-computer manufacturer NovAG, starting with the period April 1993 to March 1994. The winner of the first NOVAG AwARD was Rainer Feldmann for his Ph.D. thesis Game Tree Search with Massively Parallel Systems.

The period covered by the second Novag AwARD is April 1994 to March 1995, both limits included. The winner of the second NovAG AWARD will be announced in Vol. 18, No. 4.

13 Ballow Crescent, Macgregor, A.C.T, 2615 Australia. Email: tridge@arvidsjaur.anu.edu.au. 